\title{
EGFR NM_005228.3:c.2234_2236delAGG
}

National Cancer Institute

\section{Source}

National Cancer Institute. EGFR NM 005228.3:C.2234 2236delAGG. NCI Thesaurus. Code C98551.

A deletion of three nucleotides from the coding sequence of the EGFR gene from position 2234 through 2246. 